\title{
Fatigue Behavior of Ceramic Matrix Composite Oxidized at Intermediate Temperatures
}

\author{
Shijie Zhu \\ Department of Intelligent Mechanical Engineering, Fukuoka Institute of Technology, Fukuoka 811-0295, Japan \\ The effect of intermediate temperature oxidation on fatigue behavior of $\mathrm{SiC} / \mathrm{SiC}$ is investigated to understand fatigue damage \\ mechanisms. It has been found that fatigue life is decreased by $13 \%$ after oxidation at $600^{\circ} \mathrm{C}$ for 100 hours due to disappearance of carbon \\ interphase by oxidation. The strong bonding between the fibers and matrix caused by $\mathrm{SiO}_{2}$ formation at $800^{\circ} \mathrm{C}$ for 100 hours leads to the shortest \\ fatigue life. [doi:10.2320/matertrans.47.1965]
}

(Received April 17, 2006; Accepted July 18, 2006; Published August 15, 2006)

Keywords: ceramic matrix composite, SiC/SiC, fatigue, interface, fracture, oxidation, fiber pullout

\section{Introduction}

Fiber reinforced ceramic matrix composites (CMCs) are designed as damage tolerant materials, in which matrix cracks deflect along interfaces between fibers and matrix and redistribute stress from the matrix to fibers. ${ }^{1)}$ As a result, CMCs have high fracture toughness and inelastic deformation and no scale effects. ${ }^{1)}$ The weak interface between fibers and the matrix is vital for interfacial debonding that can be realized by carbon coating on fibers. However, the carbon interphase is easy to be oxidized at intermediate temperatures $\left(600-800^{\circ} \mathrm{C}\right)$. The oxidation embrittlement at intermediate temperatures is called "pest" phenomenon since tensile strength and creep life are markedly decreased. ${ }^{2,3)}$ After the carbon interphase is oxidized, the fibers and matrix in $\mathrm{SiC}$ fiber reinforced $\mathrm{SiC}$ matrix composite $(\mathrm{SiC} / \mathrm{SiC})$ locally react with oxygen and therefore their bonding becomes strong with the formation of silica. ${ }^{4,5)}$ A modified $\mathrm{SiC} / \mathrm{SiC}$ is fabricated by adding glassy phases in the matrix, which is called the enhanced $\mathrm{SiC} / \mathrm{SiC} .{ }^{6,7)}$ At temperatures above $1200^{\circ} \mathrm{C}$, creep and fatigue properties of the enhanced $\mathrm{SiC} /$ $\mathrm{SiC}$ in air are quite good. However, the pest phenomenon cannot be improved since the glassy phases are not able to seal cracks at intermediate temperatures. Moreover, the effects of the pest phenomenon on cyclic fatigue life are not well understood although the phenomenon is confirmed.

In this paper, effect of intermediate temperature oxidation on cyclic fatigue behavior is investigated to understand fatigue damage mechanisms. Pre-oxidation tests are conducted at $600-800^{\circ} \mathrm{C}$ to explore influence of only carbon oxidation on fatigue life.

\section{Experimental Procedures}

An enhanced $\mathrm{SiC} / \mathrm{SiC}$ composite (made by Honeywell Composites Inc., U.S.A.) was used in this investigation. The composite was processed by chemical vapor infiltration (CVI) of $\mathrm{SiC}$ into preforms of 2-directional $\left(0^{\circ} / 90^{\circ}\right)$ plainwoven Nicalon fibers with 11-plies. Before the infiltration, the preform was coated with about $1 \mu \mathrm{m}$ thick pyrocarbon by CVD (chemical vapor deposition) in order to decrease the interface bonding between fibers and the matrix leading to an
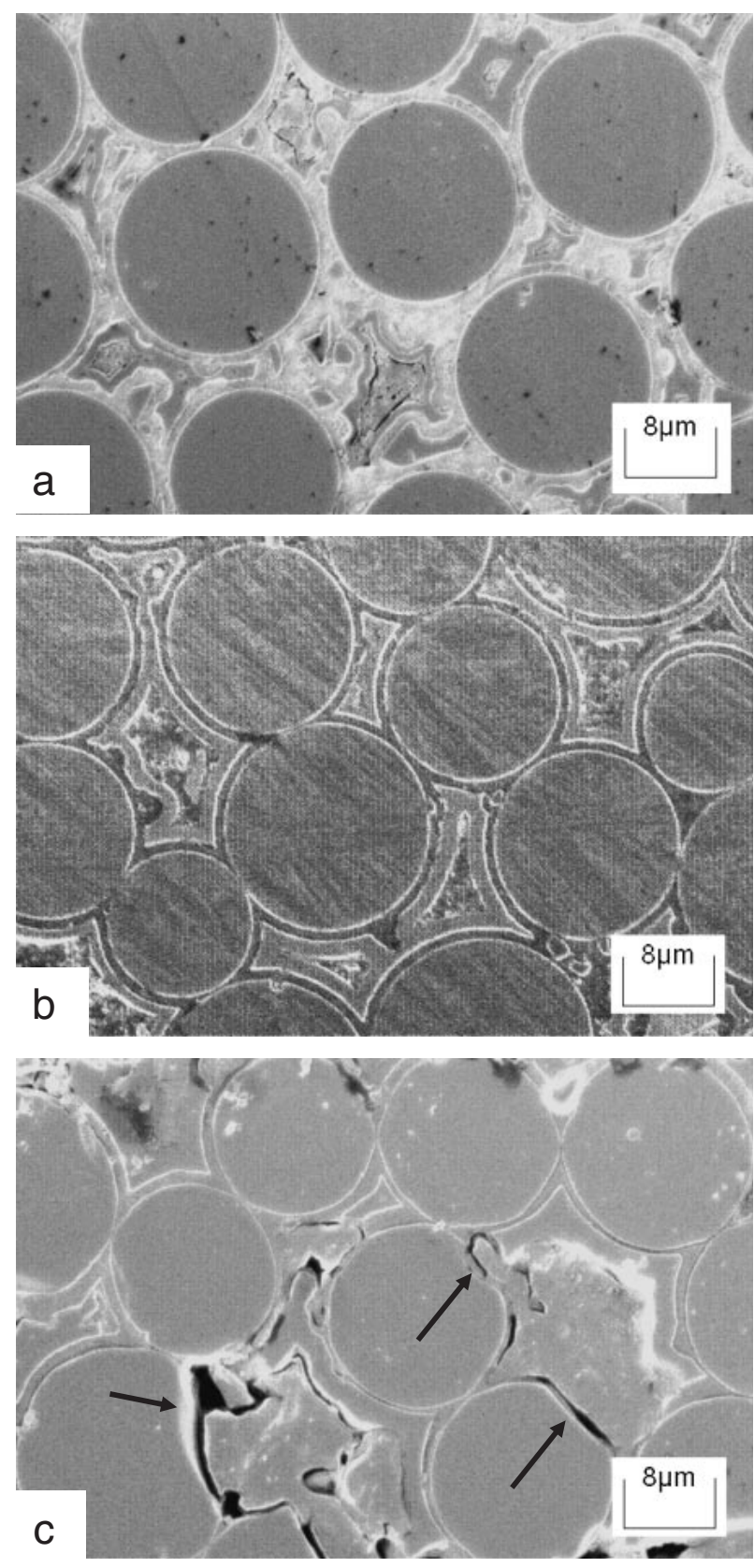

Fig. 1 Microstructures in as-received (a), oxidized $600^{\circ} \mathrm{C} \mathrm{(b)} \mathrm{and} 800^{\circ} \mathrm{C}$ (c) 
increase in toughness, and to suppress crack sensitivity by allowing crack deflection along the fiber/matrix interface. A glass-forming, boron-based particulates that react with oxygen were added to the $\mathrm{SiC}$-matrix to produce a sealant glass that inhibits oxidation of carbon layer. ${ }^{5,6)}$ The composite, processed as $200 \times 200 \mathrm{~mm}$ panels with a thickness of 3.4 $\mathrm{mm}$, contained $40 \mathrm{vol} \%$ Nicalon fibers and $10 \%$ porosity. The average diameter and tensile strength of fibers were about $12 \mu \mathrm{m}$ and $3.0 \mathrm{GPa}$, respectively. Each bundle consisted of 500 fibers with a density of $3.10 \mathrm{~g} / \mathrm{cm}^{3}$. The bulk density of the composite was $2.3 \mathrm{~g} / \mathrm{cm}^{3}$.

The specimens for fatigue tests are $3 \mathrm{~mm}$ in thickness and $4 \mathrm{~mm}$ in width and $36 \mathrm{~mm}$ in length. The oxidation tests were conducted in air using an electric furnace at $600-800^{\circ} \mathrm{C}$ for 100 hours. The microstructures and fracture surfaces were observed using scanning electronic microscope (SEM). Four point flexural fatigue tests were carried out under load control with a stress ratio of 0.1 and a frequency of $10 \mathrm{~Hz}$ in sinusoidal waveform at room temperature using servohydraulic fatigue machine.

\section{Results and Discussion}

Figure 1 shows microstructures in as-received and oxidized specimens. After oxidation at $600^{\circ} \mathrm{C}$ for 100 hours, a gap between fibers and the matrix appears due to disappearance of carbon interphase by chemical reaction: $\mathrm{C}+\mathrm{O}_{2} \rightarrow$ $\mathrm{CO}_{2}$. This is in agreement with the mass loss results after oxidation at 550 and $700^{\circ} \mathrm{C}$ by thermo-gravimetric analysis. ${ }^{4)}$

The fibers and the matrix are bonded by formation of $\mathrm{SiO}_{2}$

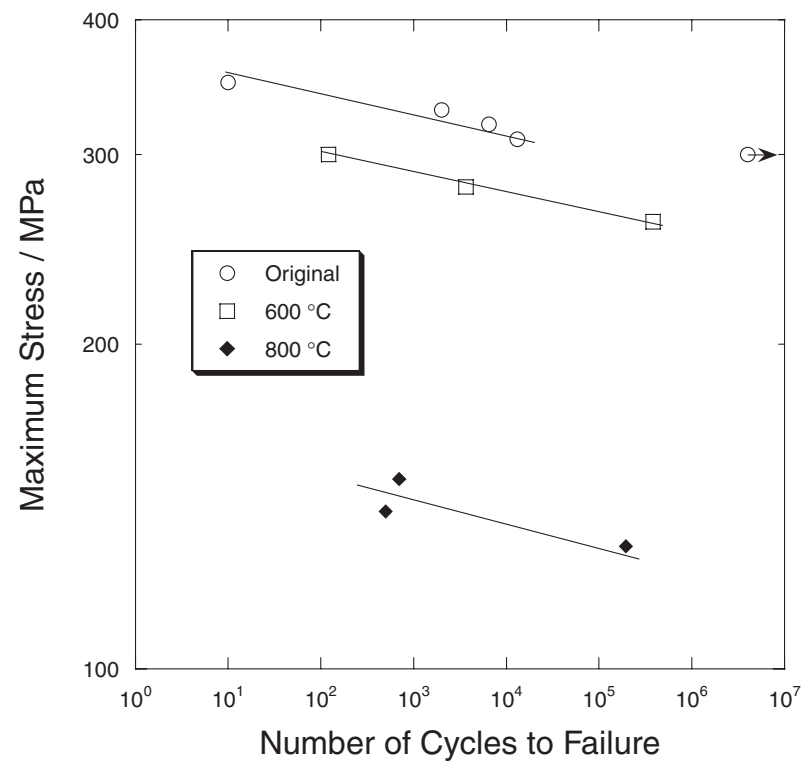

Fig. 2 The maximum stress as a function of number of cycles to failure in as-received and oxidized specimens.

after oxidation at $800^{\circ} \mathrm{C}$ for 100 hours. This is because fibers and the matrix are oxidized by the reaction: $\mathrm{SiC}+2 \mathrm{O}_{2}=$ $\mathrm{SiO}_{2}+\mathrm{CO}_{2}$ after the disappearance of carbon interphase by oxidation. The mass loss in the initial stage of oxidation at 775 and $850^{\circ} \mathrm{C}$ and then mass gain reported in reference ${ }^{4)}$ agree with the observation. Moreover, the fibers degradation and damage also occur with oxidation.
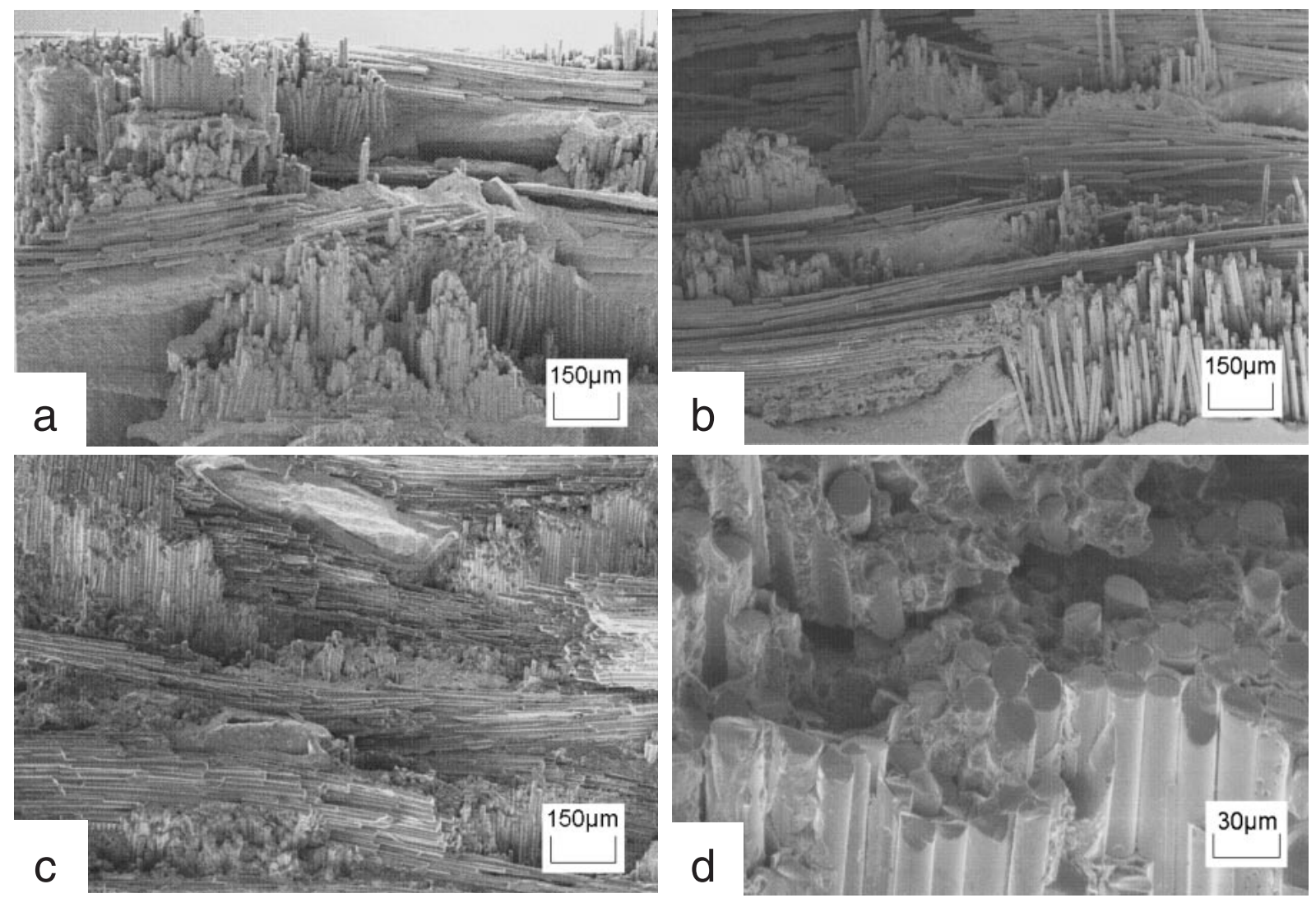

Fig. 3 Fatigue fracture surfaces in as-received (a), oxidized at $600^{\circ} \mathrm{C} \mathrm{(b),} 800^{\circ} \mathrm{C} \mathrm{(c)} \mathrm{and} \mathrm{(d).}$ 
The maximum stress as a function of number of cycles to failure is shown in Fig. 2. At a given fatigue life, fatigue strength in $600^{\circ} \mathrm{C}$ oxidized specimens is $13 \%$ lower that that in as-received specimens. While the fatigue strength after oxidation at $800^{\circ} \mathrm{C}$ is only $43 \%$ of that in as-received specimens.

From fracture surfaces, a longer fiber pullout in $600^{\circ} \mathrm{C}$ oxidized specimens can be seen compared to that in asreceived specimens, as shown in Fig. 3. This is reasonable since the interface between fibers and the matrix becomes weaker after oxidation at $600^{\circ} \mathrm{C}$ for 100 hours. Little fiber pullout can be seen after oxidation at $800^{\circ} \mathrm{C}$ for 100 hours.

Evans et ll $^{8)}$ reviewed fatigue of ceramic matrix composites at room temperature. Two possible mechanisms for CMCs were proposed: one is the changes in the interface sliding resistance during cycling; another is the degradation of the strength of the fibers by cyclic sliding along the interface by means of an abrasion mechanism, which introduces flaws in the fibers. It was found that the interface sliding resistance was decreased by cyclic fatigue in $\mathrm{SiC} /$ SiC. ${ }^{9)}$ The decrease of sliding resistance of interfaces can cause the debonding length of interfaces to increase. Both interface debonding and sliding occur under cyclic loading and unloading. The interface debonding is important for fiber bridging since it can retard fibers failure by dissipating energy (decreasing stress concentration). However, the increase in the debonding length during fatigue implies the increase in the effective fiber gauge length in the composite. This leads to fiber failure due to decreased strength of fibers. The balance between the fiber bridging in the wake of propagating crack tip and the breakage of the bridged fibers by interfacial degradation maintains a steady state cyclic crack propagation. From the fatigue mechanism in $\mathrm{SiC} / \mathrm{SiC}$, the weak interface after oxidation at $600^{\circ} \mathrm{C}$ will leads to low fatigue strength.

When the fibers are strongly bonded with the matrix after oxidation at $800^{\circ} \mathrm{C}$, the composite loses its damage tolerant characteristics and behaves as a monolithic porous ceramic. The oxidation of the fibers weakens the fibers and therefore the fatigue strength of the composite is very low. ${ }^{2}$ )

\section{Conclusions}

Cyclic fatigue life is decreased by $13 \%$ after oxidation at $600^{\circ} \mathrm{C}$ for 100 hours due to disappearance of carbon interphase by oxidation. The strong bonding between the fibers and matrix caused by $\mathrm{SiO}_{2}$ formation at $800^{\circ} \mathrm{C}$ for 100 hours leads to the shortest fatigue life.

\section{REFERENCES}

1) A. G. Evans: Acta Mater. 45 (1997) 23-40.

2) A. G. Evans, F. W. Zok, R. M. McMeeking and Z. Z. Du: J. Am. Ceram. Soc. 79 (1996) 2345-2352.

3) F. Heredia, J. McNulty, F. Zok and A. G. Evans: J. Am. Ceram. Soc. 78 (1995) 2097-2100.

4) M. Huger, D. Fargeot and C. Gault: J. Am. Ceram. Soc. 77 (1994) 25542560.

5) L. Filipuzzi, G. Camus and R. Naslain: J. Am. Ceram. Soc. 77 (1994) 459-466.

6) S. Zhu, M. Mizuno, Y. Kagawa, J. Cao, Y. Nagano and H. Kaya: J. Am. Ceram. Soc. 81 (1998) 2269-2277.

7) S. Zhu, J. Cao, M. Mizuno and Y. Kagawa: Metall. Mater. Trans. 35A (2004) 2853-2859.

8) A. G. Evans, F. W. Zok and R. M. McMeeking: Acta Metall. Mater. 43 (1995) 859-875.

9) M. Mizuno, S. Zhu, Y. Nagano, Y. Sakaida, Y. Kagawa, M. Watanabe: J. Am. Ceram. Soc. 79 (1996) 3065-3077. 